\title{
CyberKnife Sisteminde IRIS ve MLC Tabanlı Kolimatörler için Beyin Metastazlı Olgularda SRT Tedavi Planlarının Dozimetrik Karşılaştırması
}

\author{
Mehmet TOSUN, Sibel KAHRAMAN ÇETINTAŞ, Hidayetül Mediha KILIÇ, \\ Metin ZORLUTUNA, Arda KAHRAMAN, Ali ALTAY, Meral KURT, \\ Candan DEMIRÖZ ABAKAY
}

Bursa Uludağ Üniversitesi Tıp Fakültesi, Radyasyon Onkolojisi Anabilim Dalı, Bursa.

\section{ÖZET}

$\mathrm{Bu}$ çalışmanın amacı; Cyberknife ile gerçekleştirilen intrakranial tedavilerde IRIS kolimatör ve MLC ile yapılan planların kalitelerini değerlendirmek ve karşılaștırmaktır. Değerlendirme yapılırken homojenite, konformalite, gradiyent indeks, Monitör Unit ve tedavi süresi parametreleri kullanıldı. Tedavi planları oluşturulurken kritik organların maksimum derecede korunması sağlanırken reçete edilen dozun \%100'ünün, hedef hacmin \%95'ini sarmasına dikkat edildi. Beyin metastazlı 10 olgunun, iki farklı kolimatör kullanılarak farklı lokalizasyonlarda bulunan hedef hacimlere yönelik, tedavi planları yapıldı. Planlarda reçete edilen doz 3 fraksiyonda 18 Gy olarak tanımlandı. Doğru bir karşılaştırma yapabilmek için IRIS kolimatör ve MLC için kullanılan planlama parametreleri, her bir olgu için sabit tutuldu. Reçete edilen doz minumum \%80’lik izodoz eğrisine tanımlandı. HI, nCI, GI değerleri için iki ayrı planlama arasında istatistiksel anlamlı bir fark bulunmadı $(\mathrm{p}>0,05)$. CI, IRIS ile yapılan planlarda MLC'ye göre daha düşük, MU ve tedavi süreleri için ise MLC ile yapılan planlarda IRIS kolimatöre göre oldukça düşük değerler elde edildi ve istatistiksel olarak anlamlı fark vardır $(p<0,05)$. Ortalama MU değerleri sırasıyla IRIS ve MLC için; $10399 \pm 3017,3 \mathrm{MU}, 3166 \mathrm{MU} \pm 792,7 \mathrm{MU}$ ve ortalama tedavi süresi sırasıyla IRIS ve MLC için; $25 \pm$ 7,5 dk, 14,5 $\pm 2,3$ idi. İntrakranial Cyberknife tedavisinde IRIS kolimatör ve MLC için plan kalitesi karșılaștırıldığında tedavi süresi ve MU için MLC ile yapılan planlarda kalite indekslerinde kayıp olmadan tedaviyi daha az MU değeri ile daha kısa sürede bitirdiği tespit edilmiştir. Bu da olgunun daha az sürede tedavisini tamamlamasına olanak sağlamaktadır.

Anahtar Kelimeler: Beyin Metastazı. Stereotaktik Radyocerrahi. CyberKnife. Meme Kanseri. Kolimatör.

Dosimetric Application of SRT Treatment Plans in Patients with Brain Metastases for IRIS and Mlc-Based Collimators in the CyberKnife System

\begin{abstract}
ABSRACT
The purpose of this study is to evaluate and compare the quality of the plans made with IRIS collimator and MLC for intracranial treatments performed with Cyberknife. Homogeneity, conformality, gradient index, Monitor Unit and treatment time parameters were used in the evaluation. When creating treatment plans, attention was paid to the fact that $\% 100$ of the prescribed dose enveloped $\% 95$ of the target volume, while ensuring maximum protection of critical organs. Treatment plans were made for the target volumes of 10 cases with brain metastases in different localizations using two different collimators. The dose prescribed in the plans was defined as $18 \mathrm{~Gy}$ in 3 fractions. In order to make an accurate comparison, the planning parameters used for IRIS collimator and MLC were kept constant for each case. The prescribed dose was defined as a minimum isodose curve of $\% 80$. There was no statistically significant difference between the two decouples for the values of $\mathrm{HI}, \mathrm{nCI}$, GI ( $>0.05)$. CI was lower in plans with IRIS than MLC, and for MU and MLC treatment periods, quite low values were obtained in plans with IRIS collimator and there is a statistically significant difference $(\mathrm{p}<0.05)$. The mean MU values were $10399 \pm 3017.3$ $\mathrm{MU}, 3166 \mathrm{MU} \pm 792.7 \mathrm{MU}$ for IRIS and MLC, respectively, and the mean treatment time was $25 \pm 7.5 \mathrm{~min}, 14.5 \pm 2.3$ for IRIS and MLC, respectively. When the quality of the plan for IRIS collimator and MLC was compared in the treatment of intracranial Cyberknife, it was found that in the plans made with MLC for the duration of treatment and MU, the treatment was completed in a shorter time with less MU value without loss in the quality indices. This, in turn, allows the patient to complete his treatment in less time.
\end{abstract}

Key Words: Brain Metastasis. Stereotactic Radiosurgery. CyberKnife. Breast Cancer. Collimator.

Geliş Tarihi: 19.Ekim.2021

Kabul Tarihi: 02.Aralık.2021

Dr. Sibel KAHRAMAN ÇETINTAS

Bursa Uludağ Üniversitesi Tıp Fakültesi,

Radyasyon Onkolojisi Anabilim Dalı,

Bursa.

Tel: 05326565474

E-posta: skahraman@uludag.edu.tr
Yazarların ORCID Bilgileri:

Mehmet TOSUN: 0000-0002-8034-2507

Sibel KAHRAMAN ÇETINTAŞ: 0000-0002-4483-9284

Hidayetül Mediha KILIÇ: 0000-0002-0022-1140

Metin ZORLUTUNA: 0000-0001-9445-2208

Arda KAHRAMAN: 0000-0003-0150-8052

Ali ALTAY: 0000-0003-2224-9248

Meral KURT: 0000-0003-1637-910X

Candan DEMIRÖZ ABAKAY: 0000-0001-5380-5898 
Beyin metastazları en sık görülen kötü huylu beyin tümörleridir ve kanserli hastalarda önemli bir ölüm nedenidir ${ }^{1}$. İleri evre kanseri olan olgularda başlangıçta ortaya çıkan semptomların nedeni de olabilmektedir. Beyin metastazlarının çoğu akciğer, meme, kolorektal kanser, melanom ve renal hücreli karsinomdan kaynaklanır. Beyin metastazları genellikle cerrahi, radyoterapi, kemoterapi, immünoterapi ve hedefe yönelik tedavilerin bir kombinasyonunu içeren yöntemlerle tedavi edilir ${ }^{2}$. Metastatik beyin lezyonu için tedavinin birincil amacı lokal kontroldür. Fraksiyone tüm beyin radyoterapisi (TBRT) beyin metastazlarının standart bir tedavisi olmuştur; ancak sınırlı lokal tümör kontrolü ve nörokognitif fonksiyon bozukluğuna neden olmaktadır. Stereotaktik radyocerrahi yöntemi bu sınırlamaların birçoğunun üstesinden gelmektedir. Tek başına bir tedavi yöntemi olarak stereotaktik radyocerrahinin kullanılması iyi bir lokal kontrol sağ$\operatorname{lar}^{3}$. Sinırlı tümör metastazı olan ve genel sağkalım beklentisi iyi olan olgularda TBRT yerine Stereotaktik Radyocerrahi (SRC) veya Stereotaktik Radyoterapi (SRT) tercih edilmektedir ${ }^{4}$.

SRC, tek fraksiyonda hedef hacime yüksek oranda verilen radyasyon dozunu konformal olarak yapan tedavi şeklidir. Tümör çapının 2-3 cm'den küçük olan olgularda daha çok uygulanır. Çünkü tümör çapı arttıkça radyasyon nekrozu gibi toksisite riski artmaktadır. 2-3 cm'den büyük tümörlerde tümör kontrolü ve toksisite riskini azaltmak için tümör hacmine verilen total doz azaltılmalıdır ya da fraksiyone edilmelidir ${ }^{5}$.

SRT, kötü huylu veya iyi huylu tümörlerin yanı sira nörolojik fonksiyonel bozukluklar için önerilen bir tedavi yöntemidir. SRT, tümör hacmine birkaç (2-5) fraksiyonda yüksek doğrulukla ve milimetrik hassasiyetle yüksek radyasyon dozu verilen hipofraksiyone stereotaktik bir yöntemdir ${ }^{6}$. Hipofraksiyone stereotaktik radyoterapi, özellikle büyük veya kritik yapıların yakınında bulunan beyin metastazlarında, tek fraksiyonlu stereotaktik radyocerrahiye alternatif bir yöntemdir ${ }^{7}$.

Cyberknife sisteminde IRIS kolimatör, fixed kolimatörlerle aynı 12 açıklığı sağlayan ikincil kolimatördür. Fakat tek bir kolimatörde 12 sabit kolimatörün açıklıklarını bilgisayar kontrolünde ayarlayabilmekte ve mevcut olan 12 sabit kolimatör boyutunu çoğaltmaktadır. Altıgen bir açıklığa sahip 6 tungsten segmentinden oluşan iki yelpaze şeklinde oluşur. Bu kolimatörü birbirine göre $30^{\circ}$ dengelendiğinde görsel şekli kolimatörün bir ucundan diğerine bakıldığında 12 kenarl (dodekahedral) açıklık şeklinde görülür ${ }^{8}$.

Multileaf Collimator (MLC), düzgün şekilli olmayan daha büyük tümörlerin tedavisi için radyasyon alanını oluşturan ikincil kolimatördür. MLC radyasyon alanını şekillendirmek için, bağımsız hareket edebilen yapraklar kullanır. MLC'nin özellilkleri; eş düzlemli olmayan ışın hedefleme, maksimum geometrik alan boyutu $115 \mathrm{~mm}$ x $100 \mathrm{~mm}$ 'dir. $0,5^{\circ}$ eğimli ve $2,5 \mathrm{~mm}$ kalınlıktaki yapraklar, $80 \mathrm{~cm}$ kaynak eksen mesafesinde (SAD) 3,85 mm yaprak aralığı için normalize edilmiştir ve yapraklar tungstenden yapılmıştır ${ }^{8}$.

$\mathrm{Bu}$ çalışmada, CyberKnife Radyocerrahi Sisteminde beyin metastazlı on olgunun Accuray Precesion Planlama Sistemi kullanılarak sanal tedavi planları iki farklı kolimatör (IRIS Kolimatör ve MLC) için hesaplatıldı. Yapılan çalışmada radyocerrahi için önem ifade eden tedavi planlama sisteminde homojenite indeksi, konformite indeksi, gradiyent indeksi, Monitör Unit ve süre parametrelerinin karşılaştırılması amaçlanmıştır.

\section{Gereç ve Yöntem}

Bu çalışmada, Bursa Uludağ Üniversitesi Tıp Fakültesi Radyasyon Onkolojisi Anabilim Dalı'nda daha önce tedavi görmüş meme kanseri tanılı 10 beyin metastazlı olguya ait $1 \mathrm{~mm}$ kesit aralığı ile çekilen Bilgisayarlı Tomografi (BT) görüntüleri kullanılarak her bir olgu için yapılan Cyberknife sanal planlarda iki farklı kolimatör ile dozimetrik karşılaştırma yapılmıştır.

\section{Olgu Seçimi}

Olgu seçimi yapılırken meme kanserli tanılı beyin metastazlı 10 olgu çalışmaya dahil edilmiştir. Olguların tek lezyonlu ve lezyon çapları $4 \mathrm{~cm}$ 'den küçük olan tümörleri seçtik (bknz, Tablo I).

Tablo I. Lezyonun çapını, hacmini, yerini ve lokalizasyonlarını gösteren veriler

\begin{tabular}{|l|c|c|c|c|}
\hline Olgular & Çap $(\mathbf{C m})$ & Hacim $\left(\mathbf{C m}^{3}\right)$ & Yerleşim & Lokalizasyon \\
\hline 1. Olgu & 1,52 & 1,22 & Sol orta & Temporal \\
\hline 2. Olgu & 1,37 & 1,43 & Sol orta & Serbellum \\
\hline 3. Olgu & 0,94 & 1,27 & Sol orta & Serebellum \\
\hline 4. Olgu & 0,59 & 0,23 & Sağ & Pariatel Lob \\
\hline 5. Olgu & 1,68 & 1,59 & Sol & Pariatel Lob \\
\hline 6. Olgu & 2,18 & 4,28 & Sağ & Talamus \\
\hline 7. Olgu & 3,63 & 10,73 & Sağ & Temporal \\
\hline 8. Olgu & 0,95 & 0,52 & Sol & Serebellum \\
\hline 9. Olgu & 1,92 & 2,17 & Sol & Serebellum \\
\hline 10. Olgu & 2,39 & 4,79 & Sol & Pariatel Lob \\
\hline Ortalama & 1,72 & 2.82 & - & - \\
\hline
\end{tabular}

\section{Konturlama}

Olguların çekilen BT görüntüleri accuray planlama sistemine gönderildi. Ayrıca çekilmiş olan Magnetik rezonans görüntülemedeki görüntüleride planlama sistemine aktarılarak tomografi görüntüleriyle füzyon yapıldı. Radyasyon Onkoloğu tarafından hedef volümler ve riskli organlar tanımland.

\section{Accuray Precesion Planlama Sisteminde Planlama}

Olgulara Accuray precesion planlama sistemi kullanılarak iki ayrı sanal tedavi planı yapılmıştır. Planlardaki lezyonların hacim ortalaması 2,82 (0,23-10,73) 


\section{Meme Kanseri Tanılı Beyin Metastazı}

$\mathrm{cm}^{3}$ 'dür. Lezyonların ortalama çapı $1,72(0,59-3,63)$ cm'dir (Tablo I). Tedavi planına başlamak için hedef hacim ve kritik organ volümleri konturlandıktan sonra başlandı. Her olgu için yapılan planda iki farklı kolimatör kullanıldı ve $6 \mathrm{MV}$ enerji seçildi. Olgular için reçete edilen doz 3 fraksiyonda 18 Gy olarak hesaplandı. Doz dağılımını daha homojen yapması için 2 $\mathrm{mm}, 5 \mathrm{~mm}, 10 \mathrm{~mm}$ ve $15 \mathrm{~mm}$ 'lik Shell'ler oluşturuldu. İzleme algoritması olarak 6D-Skull kafa izleme algoritması kullanıldı. Planlar yapılırken planlanan tümör volümünün (PTV) en az \%95'inin verilen dozu almasina ve kritik organların alabilecekleri en az dozu almalarına dikkat edilmiştir. Şekilde Accuray Precesion planlama sistemi ile yapılan sanal plana ait iki kolimatörün (IRIS ve MLC) doz dağılımı gösterilmiştir (Şekil 1).

А)

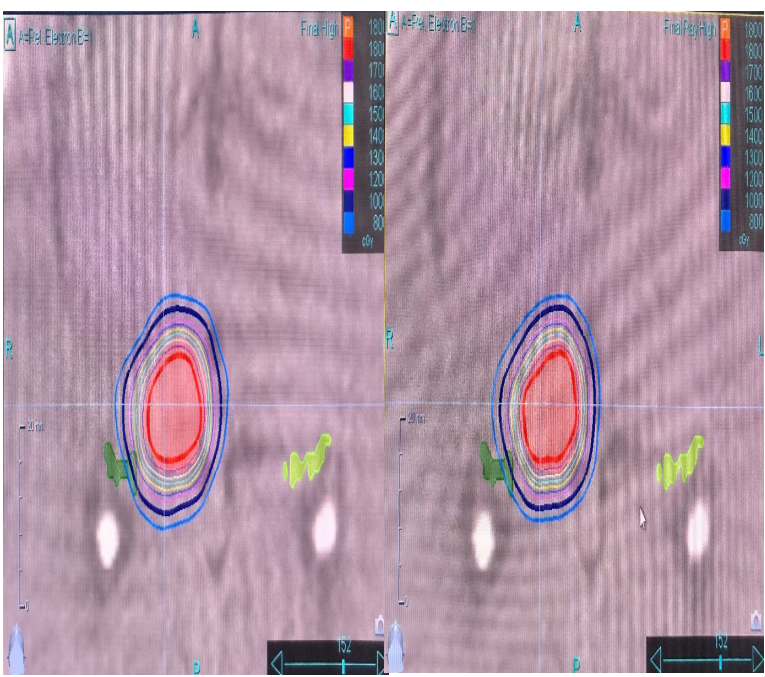

Şekil 1:

Intrakranial lezyon axial görüntüsü a) IRIS kolimatör doz dağılımı b) MLC doz dăğlımı Her iki kolimatörde de 800 ve 1000 c Gy alan izodoz eğrisine bakttğımızda

IRIS kolimatör lehine küçük farklar görebiliyoruz.

1800 dozlarına baktığımız IRIS lehine daha konformite olduğu görülebiliyor.

\section{Homojenite İndeksi (HI)}

$\mathrm{HI}$, hedef hacimdeki doz homojenliğini analiz etmek ve ölçmek için kullanılan hesaplama aracıdır.

$$
\mathrm{HI}=\mathrm{D}_{\max } / \mathrm{D}_{\mathrm{p}}
$$

$\mathrm{D}_{\max }=$ Hacmin maksimum aldı $\breve{g} 1 \mathrm{doz}$

$\mathrm{D}_{\mathrm{p}}=$ Planlanan hacimin reçete edilen dozu

1'e yakın HI değerleri daha yüksek doz homojenliğini gösterirken, l'den büyük değerler daha heterojen doz dağılımını gösterir ${ }^{9}, 10$.

\section{Konformite Indeksi (CI ve $n C I$ )}

Radyasyon Tedavisi Onkoloji Grubu (RTOG) CI, reçete edilen doz hacmi $(\mathrm{RDH})$ ile tümör hacmi $(\mathrm{TH})$ arasındaki oran olarak tanımlanır ${ }^{11} .1 .0$ ve 2.0 aral1ğında CI içeren planlar RTOG protokolüne uygundur. CI $>2.5$ veya $\mathrm{CI}<0.9$ olan planların büyük ihlalleri var, ancak yine de kabul edilebilir. $\mathrm{CI}<1$ şu anlama gelir; PTV referans doz kapsamında değildir ve $\mathrm{CI}>2$, tüm PTV'nin referans doz tarafindan kapsandığı anlamına gelir, ancak ihmal edilemeyecek kadar yüksek doz ışınlamaya sağlıklı dokular da dahildir ${ }^{9}, 12$.

$$
\mathrm{CI}_{\mathrm{RTOG}}=\mathrm{RDH} / \mathrm{TH}
$$

$\mathrm{nCI}_{\mathrm{RTOG}}$, hedef hacmin dışına çıkan referans dozunu nicelendirmez. Kabul edilebilir bir CI'ye yol açabilir, fakat reçete edilen dozu alan hedef hacim ve hedef hacim dışındaki dozu azaltabilir.

$\mathrm{CI}_{\mathrm{RTOG}}$ ile ilgili bu sorun daha sonra $\mathrm{nCI}_{\text {Paddick }}$ ile reçeteli dozu alan hedef kapsamı ve hedefin dışındaki hacmi içeren CI'yi geliştirmiş̧tir. Doz uygunluğu aşağıdaki gibi verilen ters $\mathrm{nCI}_{\text {Paddick }}$ formulasyonuna dayaniyordu ${ }^{9,12}$.

$$
\mathrm{nCI}_{\text {Paddick }}=\mathrm{TVxPV} /\left(\mathrm{TV}_{\mathrm{PV}}\right)^{2}
$$

Mükemmel uyumlu bir plan $\mathrm{CI}=1.0^{\prime}$ a yakın olanlardır ve daha az uyumlu planlar ise hedef hacmin reçeteli izodoz hacmi tarafindan sarmıș veya sarmamı̣ olmasına bağlı olarak $\mathrm{CI}<1$ veya $>1$ olacaktır $^{9,12}$.

\section{Gradiyent Indeks (GI)}

Gradiyent indeksi, düşük GI değerlerinin $(\mathrm{GI}<3)$, hedef hacim dışında daha düşük ve hedef hacimde daha iyi doz uyumluluğunu gösteren parametredir. Tek hedefli SRC planı için $\leq 3.0$ GI değeri ideal kabul edilmekle birlikte, birden çok hedeften oluşan planlar için optimum GI değerlerine ilişsin veriler tam mevcut değildir. Birden fazla hedeflerde üst üste binen $\% 50$ izodoz çizgileri ile birbirine yakın olduğunda GI değerlerinin daha yüksek olması beklenir?

$$
\mathrm{GI}=\mathrm{V}_{\% 50} / \mathrm{V}_{\% 100}
$$

GI, reçete edilen izodozun yarısının hacminin yine reçete edilen izodoz hacmine oranından hesaplanır. Bu indeks robotik radyocerrahi tedavi planlama sisteminde otomatik olarak hesaplanmaz; ancak, modifikasyonlarla hesaplanabilir: yumuşak doku hacmi doz volüm histogramı (DVH) ekranında hedef hacmi kendinden hariç tutar, örn. 25 cc'lik bir hedefin $\% 80$ izodoz çizgisine tedavi reçete ediliyorsa, GI "\%40 izodoz + 25 cc'lik yumuşak doku hacmi"nin "\%80 izodoz +25 cc'lik yumuşak doku hacmi"ne oranı olarak hesaplanabilir. Planlama sisteminde alternatif olarak 'cildi' kullanabiliriz $^{13}$.

\section{Istatiksel Veri Analiz}

Çalışmamızdaki bütün istatistiksel analizler IBM SPSS23.0 (IBM Corp. Released 2015. IBM SPSS Statistics for Windows, Version 23.0. Armonk, NY: IBM Corp.) istatistik paket programında yapılmıştır. Planlama parametreleri (tedavi süresi, MU), dozimetrik verileri (HI, CI, nCI ve GI) için tanımlayıcı istatis- 
tikler ortalama \pm standart sapma veya medyan (minimum-maksimum) olarak verilmiştir. $\mathrm{Bu}$ değişkenler için yapılan planların HI, CI, GI gibi verilerin karşılaştırılmasında ölçüm verilerinin normal dağılım gösterip göstermediğine bakmak için shapiro-wilk sig. değerlerine bakılmıştır. Normal dağılım gösteren verilerde Paired-Samples T Testi, normal dağılım göstermeyen verilerde ise Two-Related-Samples testi kullanıld1. İstatistiksel anlamlılık düzeyi $\mathrm{p}<0,05$ olarak belirlenmiştir.

\section{Bulgular}

Cyberknife sitemindeki accuray tedavi planlama sistemi kullanılarak iki farklı kolimatör ile yapılan planda HI değeri için karşılaştırıldığında istatistiksel olarak anlamlı fark bulunmamıştır ( $\mathrm{p}=0,373)$. İki kolimatörde de reçete edilen dozun hedef hacmi iyi kapsadığ1 görülmektedir. nCI değeri için karşılaştırıldığında anlam1 fark saptanmamıştır $(p=0,192)$. Medyan değerlerine bakıldığında birbirine benzer sonuç elde edildi. GI değeri için iki farklı kolimatörde yapılan planlar karş1laştırıldığında aralarında istatistiksel olarak anlaml fark bulunmamıştır $(p=0,352)$. GI ortalama değerleri de anlamlı olarak en düşük IRIS kolimatörde görülmüştür. CI değeri için iki farklı kolimatör karşılaştırıldığında istatistiksel olarak anlamlı fark saptanmıştır $(p=0,022)$. Ortalama değerlerine bakıldığında en düşük CI değerleri IRIS kolimatörde görülmüştür. MU değeri için iki farklı kolimatör karşılaştırıldığında istatistiksel olarak MLC lehine anlamlı fark bulunmuştur $(p<0,001)$. MU ortalama değeri IRIS kolimatörde yüksek görülmüştür. Süre değerleri için iki kolimatör karşılaştırıldığında istatistiksel olarak MLC lehine anlamlı fark bulunmuştur $(\mathrm{p}=0,001)$. MLC ile en düşük süre elde edilmiştir (bknz Tablo II).

Tablo II. Tanımlayıcı istatistikler ortalama \pm standart sapma veya medyan(minimum-maksimum) olarak verilmiştir.

\begin{tabular}{|l|c|c|c|}
\hline \multicolumn{1}{|c|}{ Parametreler } & IRIS & MLC & p \\
\hline $\mathrm{HI}$ & $1,17 \pm 0,46$ & $1,16 \pm 0,44$ & 0,373 \\
\hline $\mathrm{Cl}$ & $1,10(1,03-1,19)$ & $1,15(1,05-1,4)$ & 0,022 \\
\hline $\mathrm{nCl}$ & $1,19(1,09-1,47)$ & $1,19(1,11-1,26)$ & 0,192 \\
\hline $\mathrm{GI}$ & $5,13 \pm 1,55$ & $5,39 \pm 2,09$ & 0,352 \\
\hline $\mathrm{MU}$ & $10399 \pm 3017,3$ & $3166 \pm 792,7$ & $<0,001$ \\
\hline Süre (dk) & $25,0 \pm 7,5$ & $14,5 \pm 2,3$ & 0,001 \\
\hline
\end{tabular}

\section{Tartışma ve Sonuç}

Meme kanseri gibi yeni medikal tedavi ajanları ile sağkalımı uzayan kanserlerde beyin metastazları izlenmektedir. TBRT'si sonrası nükslerde ya da küçük hacim ve sayılı beyin metastazlarında SRC uygulanmaktadır. İntrakranial tümörlerin tedavi yöntemlerin- den biri de stereotaktik radyocerrahidir. Radyocerrahi sisteminde lokal kontrol önemlidir. Beyin metastazlı olgular için stereotaktik radyocerrahide lokal kontrol (\%70-90) etkili şekilde sağlanabilmektedir. Fakat tüm olgular için uygun olmayabilir. Çünkü $(>2 \mathrm{~cm})$ daha büyük hacimler için tek fraksiyon (SRC) ile tedavi edilenlerde nörolojik komplikasyon gelişme riski yüksektir $^{14}$. Bu sebeple $2 \mathrm{~cm}$ 'den büyük tümörlerde hiperfraksiyone SRT yöntemiyle toksisiteyi, radyasyon nekrozunu ve nörolojik komplikasyonları azaltılabilmektedir. Meme kanseri gibi uzun sağkalımlı kanserlerde önceden uygulanan TBRT sonrası izlenimde beyin metastazları saptanabilmektedir.

Çalışmamız için seçilen beyin metastazlı meme kanser tanılı 10 olgunun, iki farklı kolimatör (IRIS Kolimatör ve MLC) kullanılarak farklı lokalizasyonlarda bulunan hedef hacimlere yönelik, sanal tedavi planları yapıldı. 10 olgudaki lezyonların hacim ortalaması 2,82 (0,23$10,73) \mathrm{cm}^{3}$ 'dür. Hedef hacimler için reçete edilen doz 3 fraksiyonda 18 Gy olarak hesaplandı ve reçete edilen doz minumum \% 80'lik izodoz eğrisine tanımlandı. Yapılan çalışmamızda HI, CI, nCI, GI, MU ve tedavi süresi parametreleri dozimetrik olarak karşılaştırılmıştır.

Homojenite Indeks değeri belirlenen PTV hacmi için verilen dozun hacim içerisinde ne kadar homojen ve eşit oranlarla dağıldığını göstermektedir. 1.0'a yakın HI değerleri daha yüksek doz homojenliğini göstermektedir ${ }^{9,10} .2019$ yılında yapılan benzer bir çalışma ile Ermiş ve ark., (2019) 10 olguda beyin lezyonları için ortalama 10 cc'lik tedavi hacmini belirlemişlerdir. İntrakranial tedavi planlarında, reçete edilen dozu \% 53-80 arasında izodoz eğrisine 1-5 fraksiyonda 15-25 Gy olarak planlamışlardır. Çalışmalarında MLC ve IRIS kolimatör karşılaştırması yapmışlardır. HI değerini IRIS kolimatör için 1,39 iken, MLC için 1,29 olarak hesaplamışlardır ${ }^{15}$. Ermiş ve arkadaşlarının yapmış olduğu çalışmada anlamlı bir fark bulunmamıştır. Çalışmamızda iki farklı kolimatör için yapılan HI değerlendirmesinde birbirine yakın sonuçlar vermiştir ve istatistiksel olarak çalışmalarında anlamlı fark bulunmadi.

Limoges ve ark., (2017) çalışmalarında dozimetrik açıdan MLC ve IRIS kolimatör karşılaştırması yapmışlardır. Tek hedef alanı olan 10 olgu için reçeteli izodoz eğrisi \% 80 olarak belirlenmiştir. Yapılan planlar için medyan HI, MLC planları için 0,23 ve IRIS tabanlı planlar için 0,26 olarak bulunmuştur. Çalışma sonuçlarında istatistiksel sonuç vermemişlerse de IRIS tabanlı planlarda HI değerinin daha iyi olduğunu göstermişlerdir ${ }^{16}$. Çalışma sonucunun bizim çalışmamızdan farklı değerler olması hesaplatılan HI formülünün bizim çalışmamızdakinden farklı olmasından kaynaklanmaktadir.

Conformite indeks (CI), tedavi edilen hacmin, planlanan hedef hacime oranıdır. 1.0 ve 2.0 aralığında CI içeren planlar RTOG protokolüne uygundur. Tümör 
hacminin istenilen dozu sağlaması ve daha geniş alanların radyasyon almaması için CI değerleri önemlidir $^{9,12} .2019$ yılındaki Lan ve ark., (2019) çalışmalarında MLC ve IRIS kolimatör karşılaştırması yapmışlardır. Tek hedef alanı olan 15 olgu için reçeteli izodoz eğrisi \% 80 olarak ve reçete edilen dozlar 12-18 Gy (medyan, 16 Gy) olarak belirlenmiştir. Yapılan planlar için medyan CI, MLC tabanlı planlar için 1,81 ve IRIS tabanlı planlar için 1,92 olarak bulunmuştur. MLC'deki değerlerin daha iyi olduğunu bildirmişlerdir $^{17}$. Çalışmamızda IRIS kolimatörle yapılan planları daha konformal olarak saptanmakla beraber istatistiksel olarak anlamlı fark saptandı. CI değerlerindeki farkın yüksek olması çalışmalarında baktıkları izodoz eğri sınırları ve keskin doz düşüşü elde edebilmek için planlama hesaplamalarının parametrelerindeki yapılan katı sınırlamalardan dolayı olduğunu düşünmekteyiz.

Ermiş ve arkadaşları çalıșmalarında CI değeri IRIS kolimatör için 1,18, MLC için 1,26 olarak belirlenmiş ve istatistiksel anlamlı olarak IRIS kolimatör daha düşük ve daha iyi görülmüştür ${ }^{15}$. Jang ve ark., (2016) çalışmalarında MLC ve IRIS kolimatör karşılaştırması yapmışlardır. Tek hedef alanı olan 16 olgu için medyan hedef hacmi $2,3 \mathrm{cc}$ ve reçeteli izodoz hattı $\% 80$ olarak belirlenmiştir. Reçete edilen doz, 1-5 fraksiyon ile 15-25 Gy arasında değişmektedir. Çalışmalarında medyan CI, MLC tabanlı planlar için 1,34 ve koni/Irıs tabanlı planlar için 1,26 olarak bulunmuştur. Koni/Irıs bazlı planların daha iyi doz konformitesi (CI) gösterdiğini bulmuşlar ${ }^{18}$. Yapılan çalışma sonuçları bizim çalışmamızla aynı olduğu görülmüştür.

Nakamura's Conformite Indeks (nCI), tedavi edilen hacmin, planlanan hedef hacime oranıdır. CI ile aynı anlamdadır. Fakat hesaplama yöntemi farklıdır. Hesaplamada Paddick formülünü kullanılmıştır ${ }^{9,12}$. Ermiş ve ark., (2019) çalışmalarında nCI değeri IRIS kolimatör için 1,19 iken, MLC için 1,28 olan değerlerle istatistiksel anlamlı olarak IRIS kolimatör değerleri daha düşük ve üstün olarak saptanmıştır ${ }^{15}$. Çalışmamızda ise sonuçlar arasında istatistiksel olarak fark saptanmadi.

Kaliyaperumal ve ark., (2021) çalışmalarındaki beyin tümörünün ortalama tedavi hacmi $3.16 \mathrm{cc}$ idi. Reçeteli izodoz eğrisi \%70-92 arasında değişiyordu ve ortalama değer \%79 olarak belirtmişlerdir. $\mathrm{CI}_{\text {Paddick }}$ değeri FIXED kolimatör için 0,67, IRIS kolimatör için 0,63 iken, MLC için 0,51 olarak belirlenmiş. Bu çalışmada FIXED kolimatörü IRIS ve MLC ile kıyaslama yapılmıştır. CI $_{\text {Paddick }}$ için FIXED kolimatör IRIS kolimatör ile anlamlı bir fark bulunmamıştır ve MLC ile istatistiksel olarak anlamlı fark görülmüştür. Yapılan çalışmada FIXED kolimatör değerleri en iyi olduğu görülmüştür ${ }^{12}$. Çalışmamızda FIXED kolimatör karş1laştırması yapmadık. Yine de çalışma sonuçları değerlendirildiğinde bizim çalışmamızda IRIS kolimatörlü planların nCI değerlerinin MLC kolimatörlü planları arasında anlamlı fark görülmemiştir. Schmitt ve ark.,
(2017) çalışmalarında tek fraksiyonda tedavi edilen 10 olguda $1.5-9 \mathrm{~cm}^{3}$ arasında 10 beyin metastazı için bir plan karşılaştırması yapmışlardır. Recete edilen doz 18-20 Gy, izodoz \%70 olarak tanımlanmıştır. Çalışmada yapılan planda IRIS kolimatör için nCI değeri 1,07 iken, MLC için nCI değeri 1,11 olarak belirlemişlerdir. IRIS kolimatördeki değerlerin daha iyi olduğu görülmüştür ${ }^{19}$. Bizim çalışmamızda IRIS planlarının nCI değerlerini MLC planlarıyla benzer sonuç elde edilmiştir. Sonuçlar arasında istatistiksel olarak fark saptanmadi.

Gradiyent indeksi, (GI) reçete izodozu ve yarı reçete dozu arasındaki mesafe oranının bir göstergesi$\operatorname{dir}^{13}$. Benzer çalışmada Anthony Ho ve ark., (2017) 10 olgunun GI için sabit kolimatör, IRIS kolimatör ve MLC arasında karşılaştırma yapmışlardır. Genel olarak, IRIS ve MLC için GI, sabit kolimatör planlarından daha iyi bulunmuştur ${ }^{13}$. Ermiş ve ark. (2019) çalışmalarında GI değeri IRIS kolimatör için 0,334 iken, MLC için 0,367 bulunmuş ve istatistiksel anlamlı olarak IRIS kolimatör GI değeri daha düşük ve üstün bulunmuş ${ }^{15}$. Limoges ve ark., (2017) çalışmalarında GI değeri IRIS kolimatör için 3,0 iken, MLC için 2,7 bulmuşlardır. Çalışmada MLC'nin kullanılması doz gradyanını iyi sağlamışlardır ${ }^{16}$. Çalışmamızda ise GI değeri için istatistiksel olarak anlamlı fark yoktur ve sonuçlar birbirine yakın değerler çıkmıştır. Sonucun çalışmamızdan farklı olması hedef hacmin düzgün sınırlı olamaması ile ilgili olduğu düşünülmektedir.

MU tedavi süresini etkileyen parametrelerden biridir. MU ne kadar yüksek olursa tedavi süresi de artmaktadır. Bu da özellikle metastazlı, yaşlı hastalarda aynı pozisyonda durmayı ve tedavi sabitliğini sağlamayı zorlaştırır. Schmitt ve ark., (2017) yapmış olduğu çalışmasında MU değeri MLC için 4514 iken, IRIS kolimatör için 8557 olarak belirlenmiştir. MLC tabanlı planda IRIS tabanlı plana göre daha düşük MU değeri elde edilmiştir ${ }^{19}$. Jang ve ark., (2016) çalışmalarında IRIS kolimatör için MU değeri 18149 iken, MLC için 6709 olarak bulunmuş ve anlamlı olarak MLC daha düşük ve üstün görülmüşs ${ }^{18}$. Limoges ve ark., (2017) çalışmalarında MU değeri MLC tabanlı planlar için 9616 ve IRIS tabanlı planlar için 15357 olarak hesaplamışlardır ${ }^{16}$. Çalışmalar karşılaştırıldığında istatistiksel olarak MLC planlarının anlamlı ve benzer şekilde daha düşük MU değerleri bulunduğunu görmekteyiz.

Ermiş ve ark., (2019) çalışmalarında MU değeri IRIS kolimatör için 26346 iken, MLC için 11485 olarak bulunmuş ve anlamlı olarak MLC daha düşük ve üstün görülmüş ${ }^{15}$. Yapılan çalışma bizim çalışmamızdan daha fazla MU değerlerine sahiptir ve bu durum tümör hacmi ve reçete edilen dozun bizim çalışmamızdan daha fazla olması ile bağlantılı olarak değişmektedir. İstatistiksel olarak bakıldığında aynı anlamlılık bulunmuştur.

Tedavi süresinin kısa olması hastalar için avantajdır. Ermiş ve ark., (2019) yapmış olduğu çalışmasında 
süre değeri IRIS kolimatör için 56 dakika iken, MLC için 38 dakika olarak bulunmuş ve anlamlı olarak MLC daha düşük ve üstün bulunmuş ${ }^{15}$. Limoges ve ark., (2017) çalışmalarında MLC tabanlı planlar için $27 \mathrm{dk}$ ve IRIS tabanlı planlar için $35 \mathrm{dk}$ olarak bulmuşlardır. Çalışmada MLC'nin kullanılması IRIS kolimatörüne kıyasla tedavi süresinin önemli ölçüde azaltıldığı sağlanmış ${ }^{16}$. Jang ve ark., (2016) çalışmalarında ise süre değeri IRIS kolimatör için 51 dakika iken, MLC için 32 dakika olarak bulunmuş ve anlamlı olarak MLC daha düşük ve üstün bulunmuş ${ }^{18}$. Bizim çalışmamızda da benzer şekilde MLC lehine istatistiksel olarak anlamlı fark olduğu görülmüştür. Yapmış oldukları çalışmada süre değerlerinin daha yüksek olması tümör lokalizasyonu, tümör hacmi ve verilen dozun yüksekliği ile ilgili olabileceğini düşünmekteyiz. Bir başka neden ise hem tümör hacmine istenen dozu sağlayabilmek hem de aynı anda yakınındaki kritik organların minimum doz sağlamaya çalışıld1ğından dolayı sürenin arttığını düşünmekteyiz.

Sonuç olarak her durumda beyin metastazlarının Cyberknife sistemi ile yapılan planda her iki kolimatörde çok iyi bir uygunluğa sahip uygulanabilir bir plan sağlanabilmektedir. IRIS ve MLC ile yapılan planları incelediğimizde her iki kolimatörün birbirine karşı artıları ve eksileri vardır. nCI medyan değerlerine bakıldığında IRIS kolimatör ve MLC'de reçete edilen dozun hedef hacim için her ikisinde de iyi kapsadığ görülmektedir. HI için mean değerine bakıldığında IRIS kolimatör ve MLC ile benzer şekilde homojen plan yapılabildiğini görmekteyiz. GI mean değerine bakıldığında IRIS kolimatör ve MLC için hacim dış1na doz düşüşlerini benzer şekilde iyi sağladıkları görmekteyiz. Fakat bu 3 dozimetrik parametreler için iki ayrı kolimatörle yapılan planlarda anlamlı fark saptanmadı. CI medyan değerlerine bakıldığında IRIS kolimatörde daha düşük ve reçete edilen dozun hedef hacimi daha iyi sardığı görülmüştür. MU değerleri ve tedavi süresi için bakıldığında MLC ile yapılan planların üstün ve avantajlı olduğunu görmekteyiz. Tedavi süreleri olgular için önemli parametredir. Çünkü iyi bir tedavi sonucu için tedavi süresi boyunca olgunun hareketsiz kalması önemlidir. IRIS kolimatör ile riskli organ koruması ve doz sarımı daha iyi olabilmekle birlikte bunun MLC'ye anlamlı bir üstünlüğünü saptamadık. Tedavi süresinin kısalığı özellikle yaşlı, stabil durma zorluğu olan hastalarda tercih edilmesi uygundur. Sonuçta IRIS kolimatör ve MLC ile yapılan plan karşılaştırmasında HI, nCI ve GI değerleri birbirlerine yakın değerler elde edilmiştir. CI için IRIS kolimatörde, MU ve tedavi süresi için ise MLC'de daha iyi olduğu görülmüştür. Hangi kolimatörün seçileceği olgudaki tümörün hacmi, çapı, lokalizasyonu ve çevre kritik organlarının durumu değerlendirilerek karar verilmelidir.
Etik Kurul Onay Bilgisi:

Onaylayan Kurul: Uludağ Üniversitesi Tıp Fakültesi Klinik Araştırmalar Etik Kurulu

Onay Tarihi: 22 Eylül 2021

Karar No: 2021-13/18

Araştırmacı Katkı Beyanı: Fikir ve tasarım: S.K.C.., M.T.; Veri toplama ve işleme: M.T., M.Z., H.M.K.; Analiz ve verilerin yorumlanması: M.T., S.K.Ç., C.D.A., M.K., A.K., A.A.; Makalenin önemli bölümlerinin yazılması: S.K.Ç., M.T.

Destek ve Teşekkür Beyanı: Bu makalede yer alan çalışmalarda herhangi bir kurum tarafından finansal destek sağlanmamıștır. Çıkar Çatışması Beyanı: Makale yazarlarının çıkar çatışması beyanı yoktur

\section{Kaynaklar}

1. Fares, J., Cordero, A., Kanojia, D., \& Lesniak, M. S. The network of cytokines in brain metastases. Cancers. (2021);13(1), 1-17

2. Achrol, A. S., Rennert, R. C., Anders, C., Soffietti, R., Ahluwalia, M. S., et al. Brain metastases. Nature Reviews Disease Primers. (2019);5(1).

3. Gaspar, L. E., Mehta, M. P., Patchell, R. A., Burri, S. H., Robinson, P. D., et al. The role of whole brain radiation therapy in the management of newly diagnosed brain metastases: A systematic review and evidence-based clinical practice guideline. Journal of Neuro-Oncology. (2010); 96(1), 17-32.

4. Lippitz, B., Lindquist, C., Paddick, I., Peterson, D., O’Neill, K., et al. Stereotactic radiosurgery in the treatment of brain metastases: The current evidence. Cancer Treatment Reviews. (2014); 40(1), 48-59.

5. Lehrer, E. J., Peterson, J. L., Zaorsky, N. G., Brown, P. D., Sahgal, A., et al. Single versus Multifraction Stereotactic Radiosurgery for Large Brain Metastases: An International Meta-analysis of 24 Trials. International Journal of Radiation Oncology Biology Physics. (2019); 103(3), 618-630.

6. Guckenberger, M., Baus, W. W., Blanck, O., Combs, S. E., Debus, J., et al. Definition and quality requirements for stereotactic radiotherapy: consensus statement from the DEGRO/DGMP Working Group Stereotactic Radiotherapy and Radiosurgery. Strahlentherapie Und Onkologie. (2020); 196(5), 417-420.

7. Loo, M., Pin, Y., Thierry, A., \& Clavier, J. B. Single-fraction radiosurgery versus fractionated stereotactic radiotherapy in patients with brain metastases: a comparative study. Clinical and Experimental Metastasis. (2020); 37(3), 425-434.

8. CyberKnife. CyberKnife Treatment Delivery System. Biomedical Safety \& Standards. (2018); 40(20), 156.

9. Narayanasamy, G., Stathakis, S., Gutierrez, A. N., Pappas, E., Crownover, R., et al. A Systematic Analysis of 2 Monoisocentric Techniques for the Treatment of Multiple Brain Metastases. Technology in Cancer Research and Treatment. (2017); 16(5), 639-644

10. Yan, L., Xu, Y., Chen, X., Xie, X., Liang, B., et al. A new homogeneity index definition for evaluation of radiotherapy plans. Journal of Applied Clinical Medical Physics. (2019); 20(11), 50-56.

11. Shaw, E., Kline, R., Gillin, M., Souhami, L., Hirschfeld, A., et al. Radiation therapy oncology group: Radiosurgery quality assurance guidelines. International Journal of Radiation Oncology, Biology, Physics. (1993); 27(5), 1231-1239.

12. Kaliyaperumal, V., Abraham, S., Veni, M., Banerjee, S., Tamilselvan, S., et al. Dosimetric comparison of robotic and linear accelerator multi-leaf collimator-based stereotactic radiosurgery for arteriovenous malformation. Journal of Medical Physics. (2021); 46(1), 16-25. 


\section{Meme Kanseri Tanılı Beyin Metastazı}

13. Ho, A., Soltys, S. G., Lo, A., \& Chang, S. D. Implementation of the Gradient Index in Robotic Radiosurgery Treatment Planning. (2017); 4.

14. Lupattelli, M., Alì, E., Ingrosso, G., Saldi, S., Fulcheri, C., Borghesi, S., et al. Stereotactic radiotherapy for brain metastases: Imaging tools and dosimetric predictive factors for radionecrosis. Journal of Personalized Medicine. (2020); 10(3), $1-13$.

15. Ermiş, E., Blatti-Moreno, M., Leiser, D., Cihoric, N., Schmidhalter, D., et al. Dose analysis of InCise 2 multi leaf collimator and IRIS-based stereotactic radiotherapy plans for brain and liver tumors. Biomedical Physics and Engineering Express. (2019); 5(3).

16. Limoges, C., Bellec, J., Delaby, N., Perdrieux, M., Jouyaux, F., et al. PO-0826: Evaluation of the new InCise MLC for Cyberknife stereotactic radiotherapy. Radiotherapy and Oncology. (2017); 123, S444.
17. Lan, J. H., Shieh, C. S., Liu, C. H., Cho, I. C., Tsai, I. H., et al. Plan Quality and Secondary Cancer Risk Assessment in Patients with Benign Intracranial Lesions after Radiosurgery using the CyberKnife M6 Robotic Radiosurgery System. Scientific Reports. (2019); 9(1), 1-10.

18. Jang, S. Y., Lalonde, R., Ozhasoglu, C., Burton, S., Heron, D., et al. Dosimetric comparison between cone/Iris-based and InCise MLC-based CyberKnife plans for single and multiple brain metastases. Journal of Applied Clinical Medical Physics. (2016); 17(5), 184-199.

19. Schmitt, D., El Shafie, R., Klüter, S., Arians, N., Schubert, K., et al. Treatment planning for MLC based robotic radiosurgery for brain metastases: Plan comparison with circular fields and suggestions for planning strategies. Current Directions in Biomedical Engineering. (2017); 3(2), 151-154. 
